\title{
Soil Water Retention Properties as the Key Driver for Rehabilitation
}

\author{
R. Hattingh Ticor South Africa, KwaZulu Natal, South Africa \\ C. Viljoen Viljoen and Associates, South Africa
}

\section{INTRODUCTION}

Ticor South Africa is a heavy minerals mining and beneficiation operation on the east coast of South Africa. The company commenced operations in April 2001 with the opening of Hillendale Mine. This particular operation has a limited life (10 years), with the result that closure planning commenced four years after mining started. The pre-mining land use is commercial sugar cane production, and the measurement of postmining rehabilitation success is therefore quantifiable.

South Africa has a rapidly evolving legislation with regards to environmental issues. Major revisions of the national statutes regulating water consumption and use, mine environmental management, air quality management, biodiversity and general environmental management have taken place in the past decade. To compound the situation the different aspects are governed by a number of government departments. Although the state has made efforts to defragment the legislative environment, we still have a situation where the goalposts are changing and an operation is answerable to a host of regulators, with few or no standards against which the success of rehabilitation may be measured. Obtaining final mine closure in this specific context could therefore be problematic. For these reasons we decided to develop a rehabilitation and closure strategy from first principles. A series of workshops were held incorporating scientists from a number of backgrounds. From the workshops a strategy was compiled and series of projects generated aimed at achieving closure of the operations within two years of operations ceasing. This closure strategy as well as subsequent work showed that the soil water retention properties of the top layer of the backfilled dunes are one of the most important issues to address during rehabilitation.

The intent of this paper is to introduce the concept of a phased, fundamental approach to rehabilitation, as dictated by the key drivers in the system.

\section{BASIC PRINCIPLES AND AREA CHARACTERISTICS}

\subsection{Background}

Strategically Ticor South Africa divided rehabilitation into four aspects, namely physical rehabilitation (restoration of soil structure), vegetative rehabilitation (restoration of vegetative cover), ecological rehabilitation (restoration of sustainable ecological communities) and sustainability (sustainable man/environment interface). Our closure strategy showed that the soil water retention properties of the top layer of the backfilled dunes are an important issue to address during rehabilitation. The key performance indicators for the restoration of soil structure as identified during the technical workshops include defining the post mining variables and variance for the soil profile, physics and chemistry on the basis of the premining environment, and the development of a technical and economically achievable deposition methodology.

It must however be stressed that water retention is not evaluated in isolation relative to other processes potentially impacting on saturated and unsaturated water movement through the soil column. Furthermore, the approach has been adopted to research water holding capacity within a cost effective research protocol to address related physical, chemical and mechanical issues and changes associated with translocation soil forming processes. 


\subsection{Process of Pedogenesis and Relevance to Mining Operations}

Soils are formed through the processes of transformation and translocation. Transformation processes take place in situ but may involve some movement over very short distances (micron to millimetre scale). The physical and biological processes involved include weathering, mineral formation, decomposition of organic material, humification, pedological formation, ion exchange and reduction-oxidation processes. Various combinations of these factors are involved in the formation of the soil body from mineral and organic parent materials, and also result in the differentiation of soil into distinct horizons. Examples are accumulation of humus in topsoil, staining through liberation of iron in subsoil, with mobilisation before and immobilisation after translocation. Translocation involves the displacement, sorting and mixing within and on the soil body, resulting in profile differentiation. Factors contributing to this include percolation, erosion, fluctuating water table, anthropogenic impacts and biological activity. Translocation starts with mobilisation and ends with the relative immobilisation of transported materials.

The Hillendale orebody is mined by means of a hydraulic method, where water is used under high pressure to slurrify the ore. Run of mine is gravitated via launders to pump stations. The high clay content $(20 \%$ to $30 \%$ ) of the orebody facilitates this process. Prior to mining approximately $300 \mathrm{~mm}$ of topsoil is stripped and stockpiled for later use. Sand, clay and heavy minerals are separated, the sand is returned to the mining void and the clay fraction is disposed in a residue dam. The original plan was to replace the topsoil layer on the backfilled sand and return the area to sugar cane production. Mining in this instance therefore represents an extreme case of mobilisation, where the entire soil structure is disturbed, and its main characteristics destroyed with the exception of the topsoil layer.

\subsection{Defining the Pre- and Post-Mining Soil Variables}

In terms of the rehabilitation strategy, the pre-mining soil variables critical to sustainable rehabilitation needed to be defined in order to determine the specification for the restored soils. The original soil survey completed prior to mining identified two main soil forms on the basis of 269 sampling positions based on a $100 \mathrm{~m}$ grid. Soils were identified using a hand auger to a depth of $1.5 \mathrm{~m}$ (Snyman, 2001). Soil profiles were classified to form and family level using the South African Soil Classification System. The two main forms identified comprised Hutton (orthic topsoils on red apedal subsoils) and Clovelly (orthic top soils on yellow apedal subsoils). Topsoils were constantly medium to fine grained sand overlying heavier textured sandy clay loam to clayey subsoils. The topsoil structure was identified to consist of a single grain structure while subsoils were apedal. The soils were further classified as being dystrophic (well weathered) with base status less than $5 \mathrm{cmol}+/ \mathrm{kg}$ clay. Exchangeable cations $(\mathrm{Ca}, \mathrm{Mg}, \mathrm{K}$ and $\mathrm{Na}$ ) were low, however, some mesotrophic variants occurred. The exchangeable sodium percentage and electrical conductivity was consistently low, indicating no salt contamination. Topsoil carbon was low to medium (less than $0.3 \%$ ), probably as a result of the intensive agricultural practice in the area.

The fine fraction of the Hillendale orebody is dominated by clay minerals. In general these minerals are layer silicates of colloidal size ( $<2$ micron), with a large surface area, the ability to take up and yield water molecules, and the ability to swell and shrink. They are plastic and can adsorb exchangeable ions. Together with organic matter they give soil the ability to hold water and nutrients and give it structure. In the Richards Bay area, smectite dominated dunes have been found to be younger than the kaolinite dominated dunes (Ware et al., 2001). Northern KwaZulu-Natal currently has a hot-humid subtropical climate where hydrolysis is the dominant weathering agent. Under these climatic conditions, strong hydrolysis to the formation of kaolinite, often with associated goethite, independent of the source material weathered may take place (Chamley, 1989). The presence of magnetite, other Fe-Ti-oxides and Fe-silicates create obvious weathering sources of goethite and hematite. The $\mathrm{pH}$ of the dune sands is also important in weathering. The presence of calcite in the upper reaches of the intermediate and coastal dunes result in them being slightly alkaline (Tinley, 1986) with calcite acting as pH buffer. Kaolinite is noted by Birkland (1984) to be stable under these $\mathrm{pH}$ conditions.

A further site assessment and survey was conducted by means of the selective sampling of pre- and postmining material, with a specific focus on the two dominant soil forms as well as the footwall. The latter was included since, in the worst case, if soils can not be reconstructed from backfill and discard material, then the footwall is a potential source of material to cover the backfilled sand. The materials were analysed by means 
of standard South African soil analytical procedures in order to assess the physical, chemical and mineralogical properties of the material. The main objective of the second study was to determine the soil water retention properties of the material. From this survey it was determined that both pre-and post-mining material were characterised by predominantly kaolinite, which in terms of Ware et al. (2001) is typical of old matured sand dune deposits.

The last aspect to consider is that the pre-mining environment is used for dryland sugar cane production. This is also the desired post-mining land use. The area was historically divided up into blocks, and accurate records exist at the local sugar mill in terms of historical yields, typically expressed as tons per hectare. These records form the basis of the key performance indicator relating to the success of the rehabilitation effort.

\subsection{Water Retention Properties of the Soils at Hillendale}

The water balance of a soil depends on effective rainfall (rainfall minus interception in plant canopy), surface run-off, ease of infiltration, water holding capacity, percolation, and losses by transpiration through plants and by evaporation from the soil surface. Surface drainage takes place via ditches, streams and rivers. The water which infiltrates into the soil is partly retained as bound water and partly percolates down through the soil, accumulating as ground water below the water table. Groundwater can however rise by means of capillary action to replenish the stock of bound water. Retention of soil water is one of the most critical aspects in the rehabilitation planning for Hillendale. According to Hillel (1982) soil water is important from an ecological perspective, by meeting the water needs of plants and in terms of nutrient transport, and from a pedological perspective due to its importance in all processes of soil genesis (for example in weathering, humus enrichment, mobilization and transport).

Water retention of the soil samples was determined in accordance with the pressure plate method and principles as described by Klute (1986). The relation between the soil water content and the water suction is a fundamental part of the characterisation of the hydraulic properties of a soil (Klute, 1986). The relationship is identified in the literature by various names, including water retention function, moisture characteristics and the capacity pressure saturation curve. The function relates a capacity factor (water content) to an intensity factor (the energy state of the soil water). Since the structure of the sample affects the water retention, especially the low suction range, it is generally best to use samples of natural structure. A $75 \mathrm{~mm}$ diameter core sampler was used to obtain soil samples of a relatively undisturbed structure to generate sample dimensions of approximately 50 to $80 \mathrm{~mm}$ in diameter and 10 to $30 \mathrm{~mm}$ high.

Water retention data may be expressed in units of energy per unit mass, energy per unit volume, or energy per unit weight of the soil water. Energy per unit volume is dimensionally equivalent to force per unit area or pressure and according to Klute (1986) energy per unit weight has dimensions of length. Data in Table 1 are expressed in percentage, for example $4 \mathrm{ml}$ of water per $100 \mathrm{~g}$ soil. Table 1 illustrates the water retention data of the pre-mining Hutton and Clovelly soil forms taken at $300 \mathrm{~mm}$ depth increments up to $1800 \mathrm{~mm}$ for each form. Footwall samples represent the post mining material. The water retention profile indicated low water retention for all soil layers, even at depth where accumulation of clay material was expected to occur. The yellow, less weathered footwall showed lower water retention, as could be expected from this relatively permeable material. The relatively small difference between $33 \mathrm{kPa}$ and $1500 \mathrm{kPa}$ is indicative of low soil water retention capabilities. These data will be validated and confirmed statistically as more information becomes available. 
Table 1

Water retention data expressed as a percentage of water in the original soil forms as well as footwall samples

\begin{tabular}{|c|c|c|c|c|}
\hline Sample & $33 \mathrm{kPa}$ & $80 \mathrm{kPa}$ & $500 \mathrm{kPa}$ & $1500 \mathrm{kPa}$ \\
\hline Hutton@300mm & 4.39 & 4.18 & 3.47 & 2.43 \\
\hline Hutton@600mm & 3.99 & 3.84 & 3.43 & 3.31 \\
\hline Hutton@900mm & 3.09 & 3.29 & 2.42 & 2.27 \\
\hline Hutton@1200mm & 9.92 & 9.02 & 6.86 & 6.95 \\
\hline Hutton@1500mm & 3.39 & 3.43 & 2.63 & 2.46 \\
\hline Hutton@1800mm & 4.68 & 4.41 & 2.61 & 2.57 \\
\hline Clovelly@300mm & 8.87 & 8.70 & 6.48 & 6.39 \\
\hline Clovelly@600mm & 8.06 & 6.88 & 5.34 & 5.19 \\
\hline Clovelly@900mm & 7.52 & 5.62 & 4.89 & 4.31 \\
\hline Clovelly@1200mm & 6.29 & 5.66 & 4.73 & 4.63 \\
\hline Clovelly@1500mm & 6.49 & 4.89 & 4.03 & 3.91 \\
\hline Clovelly@1800mm & 6.56 & 5.48 & 4.55 & 4.29 \\
\hline Red footwall & 4.84 & 4.08 & 3.16 & 3.25 \\
\hline Yellow footwall & 2.21 & 2.07 & 1.54 & 1.48 \\
\hline
\end{tabular}

\subsection{General Climatological Considerations}

The regional climate can be described as subtropical and very humid with moderate rainfall. The long-term average total annual rainfall is approximately $1150 \mathrm{~mm}$. The area falls within a summer rainfall region, with approximately $60 \%$ of the annual rainfall occurring from October to February. Ambient temperatures range from an average of $11^{\circ} \mathrm{C}$ to $30^{\circ} \mathrm{C}$. The annual mean temperature for Richards Bay is $16.1^{\circ} \mathrm{C}$. A detailed analysis of rainfall variation in this region was completed for an area approximately $25 \mathrm{~km}$ south of Hillendale, and the results are presented in Table 2. From the table it is evident that the annual variation can be considerable, ranging from $550 \mathrm{~mm}$ per year to $2356 \mathrm{~mm}$ over the 84 year period that data were accumulated. 
Table 2

Percentage of time a rainfall amount is exceeded, and the maximum, minimum and average monthly rainfall amounts $(\mathrm{mm})$

\begin{tabular}{|l|c|c|c|c|c|c|c|c|c|c|c|c|c|}
\hline & Oct & Nov & Dec & Jan & Feb & Mar & Apr & May & Jun & Jul & Aug & Sep & Total \\
\hline Maximum & 314 & 448 & 619 & 424 & 421 & 619 & 547 & 421 & 564 & 370 & 165 & 701 & 2356 \\
\hline $\mathbf{1 0 \%}$ & 170 & 197 & 190 & 220 & 284 & 239 & 186 & 133 & 115 & 104 & 109 & 190 & 1474 \\
\hline $\mathbf{2 0 \%}$ & 120 & 140 & 141 & 161 & 185 & 131 & 91 & 87 & 63 & 60 & 57 & 104 & 1261 \\
\hline $\mathbf{5 0 \%}$ & 96 & 115 & 111 & 119 & 104 & 100 & 71 & 48 & 45 & 40 & 44 & 69 & 1107 \\
\hline Average & 104 & 117 & 122 & 127 & 138 & 126 & 90 & 70 & 59 & 52 & 50 & 89 & 1146 \\
\hline $\mathbf{7 0 \%}$ & 72 & 82 & 75 & 78 & 68 & 68 & 45 & 30 & 20 & 23 & 27 & 40 & 658 \\
\hline $\mathbf{9 0 \%}$ & 42 & 37 & 53 & 50 & 33 & 27 & 16 & 11 & 12 & 8 & 10 & 12 & 798 \\
\hline $\mathbf{9 8 \%}$ & 25 & 21 & 31 & 29 & 19 & 17 & 11 & 0 & 2 & 1 & 0 & 7 & 685 \\
\hline Minimum & 13 & 10 & 0 & 13 & 6 & 12 & 0 & 0 & 0 & 0 & 0 & 5 & 550 \\
\hline
\end{tabular}

\section{DETERMINATION OF IDEAL SOIL CHARACTERISTICS}

Sugar cane (Saccharum officinarum) is grown profitably in the Hillendale area on the pre-mining soils. From our field observations this specialised perennial grass has a relatively shallow rooting depth, with approximately $80 \%$ of the biomass occurring within the first 350 to $450 \mathrm{~mm}$. In general the soils in the area are well structured. Given that backfilled sands would have a relatively low water retention relative to the natural soil form, it is therefore important to define the ideal reconstituted soil primarily based on its water retention properties, but also with due consideration to soil structure, nutrient status and soil texture.

From a sustainability perspective the post-mining landform should be such that dryland agriculture can be practised under the range of normally occurring conditions. It is our perception that provided sufficient erosion protection measures are in place to minimise impact under high rainfall conditions, the challenge would be to ensure adequate yields during low rainfall conditions. This perception is based on initial work conducted at Hillendale during 1998, when two plots (control and mined area) were used to determine sugar cane yields on areas disturbed by mining (Fortmann, 1998). From this work it was concluded that yields could be similar to the pre-mining environment. However, the year following the initial experiment was dry, with the result that the first ratoon on the two plots showed radical differences between the control and the disturbed area, with the latter only yielding approximately $30 \%$ of the sucrose obtained in the control plot.

From the discussion above it is therefore important to understand (a) what the ideal reconstituted soil matrix should look like and (b) to what depth the reconstituted soil should cover backfilled sands.

\subsection{Determining the Ideal Reconstituted Soil Matrix}

Soil structure results from the manner in which irregularly shaped mineral and organic particles are arranged in relation to each other, and form the relationship between the volume of solid material and the volume of the pores which permeate the solid material. The pore volume is filled with varying proportions of air and water, and is the ratio of pore space to the volume of solid material. This is amongst others a function of packing, which in turn is influenced by particle size distributions as well as the mode of deposition. The Hillendale deposit consists of material with a bimodal distribution, with relatively few particles in the range from 10 to 125 micron (approximately 18 of the total), as is evident from the particle size distributions in Table 3. The particle size distribution of the soil samples was determined by the hydrometer method and principles as described by Gee and Bauer (1886).

Since a predominance of large particles provide a low total pore space but many pores, and is therefore highly permeable, and a predominance of small particles yield a large total pore space with many fine pores, 
which is fairly impermeable, the ideal mixture is somewhere between these two extremes. In order to achieve the pre-mining soil texture, it is therefore required that the deposition method achieve a pore space ratio of $50 \%$ (solids : pores $=1: 1$, large pores : medium + fine approximately $2: 3$ ). Due to the lack of particles in the intermediate region, the mixture most likely to be acceptable should consist of approximately $30 \%$ fine material and $70 \%$ backfilled sand. The determination of this mixture largely based on the pre-mining environment.

\section{Table 3 Particle size distributions in the vicinity of Hillendale Mine as determined by} sieving

\begin{tabular}{|c|c|c|c|c|}
\hline $\begin{array}{c}\text { Screen Size } \\
\text { (in micron) }\end{array}$ & $\begin{array}{c}\text { Orebody } \\
\text { 1\% passing }\end{array}$ & $\begin{array}{c}\text { Orebody } \\
\text { 2\% passing }\end{array}$ & $\begin{array}{c}\text { Orebody } \\
\text { 3\% passing }\end{array}$ & $\begin{array}{c}\text { Average } \\
\text { \% passing }\end{array}$ \\
\hline 600 & 99.5 & 99.4 & 99.4 & 99.4 \\
\hline 425 & 98 & 96.7 & 98.4 & 97.7 \\
\hline 300 & 79.4 & 77.3 & 90.1 & 82.3 \\
\hline 212 & 52.8 & 49.6 & 57.9 & 53.4 \\
\hline 125 & 36.2 & 36.2 & 40.8 & 37.7 \\
\hline 106 & 32.6 & 33.8 & 39.4 & 35.3 \\
\hline 90 & 30.6 & 32.1 & 37.3 & 33.3 \\
\hline 75 & 29.8 & 31.3 & 36.1 & 32.4 \\
\hline 45 & 28.3 & 29.3 & 33.0 & 30.2 \\
\hline 38 & 27.9 & 28.7 & 32.0 & 29.5 \\
\hline 30 & 23.9 & 23.7 & 27.7 & 25.1 \\
\hline 20 & 20.9 & 20.4 & 24.1 & 21.8 \\
\hline 10 & 17.6 & 17.7 & 21.0 & 18.8 \\
\hline
\end{tabular}

\subsection{Determining a Theoretical Ideal Cover Depth}

In order to arrive at the ideal cover depth, the water retention properties of various cover thicknesses needed to be evaluated. The main rehabilitation outcome is sustainable sugar cane production, and the materials available for establishing the cover required over the backfilled sands are sand and clay. The proportion required is as described above ( $70 \%$ sand to $30 \%$ clay). These parameters were therefore considered in the evaluation of cover thickness. Various cover thicknesses were modelled using the methodology described below. While the initial results indicated that a cover thickness of $1800 \mathrm{~mm}$ would be sufficient, it was decided to err on the conservative side and a final thickness of $2000 \mathrm{~mm}$ was agreed on by mine management.

We used a soil water balance model to assess the depth to which the soil profile should be reconstructed to. Soil Water Balance (SWB) is a mechanistic, multi-layer, daily time step, soil water-salt balance-generic vegetation growth model, developed from NEWSWB, a modified version of the model published by Campbell and Diaz (1988). A cascading soil water balance is used once canopy interception and surface runoff have been accounted for. Each soil layer is assumed to fill to saturation, and then pass on a portion of the water between field capacity and saturation to the layer below. Any water which passes beyond the bottom layer is assumed lost to drainage, which is a fair assumption in the specific conditions here where the permeability of the backfilled sands is much higher than that of the cover material. Potential evapotranspiration (PET) is calculated as a function of daily average air temperature, vapour pressure deficit, radiation and wind speed, adopting the FAO Penman-Monteith methodology (Allen et al., 1998). The two 
components of PET (potential evaporation and potential transpiration) are estimated from canopy cover. Actual transpiration is determined on a daily basis as the lesser of root water uptake or maximum loss rate. Total soil water potential is used to determine the amount of water available for vegetation transpiration in each soil layer. The osmotic effect on vegetation growth is simulated by adding osmotic potential to the matric and gravitational soil water potentials. Osmotic potential is calculated as a function of ionic concentration. The daily dry matter increment $\left(\mathrm{DM}_{\mathrm{i}}\right)$ is taken as the minimum of the transpiration limited (Tanner and Sinclair, 1983) and radiation limited DMi (Monteith, 1977). In SWB, salt redistribution assumes complete mixing of irrigation and rainfall with the soil solution of the top soil layer and similarly for the soil solution percolating to the next lower layer. Leaching of salts is calculated from the amount and quality of drainage. Chemical precipitation/dissolution of lime and gypsum is calculated on a daily time step per soil layer, using the model published by Robbins (1991). Electrical conductivity is calculated from individual ion concentrations (McNeal et al., 1970) for each soil layer, and are adjusted for saturation conditions as a function of soil water content. Root density weighted electrical conductivity at saturation (EC) is then calculated from each soil layer electrical conductivity and the fraction of the total root length in that layer (Campbell and Diaz, 1988).

Weather data were generated using CLIMGEN, a two-component weather generator (GS Campbell, Washington State University, USA), a modified version of WGEN (Richardson and Wright, 1984). The first component (CLIMPAR) determines statistical parameters required for long-term daily weather data generation, whilst the second component (CLIMGEN) generates weather data. CLIMGEN generates daily maximum and minimum air temperature, as well as precipitation from either historic daily weather data, if available, or from monthly averages. At least 20 years of rainfall and 10 years of historic temperature data are required in order to get a reliable simulation. The CLIMGEN weather data generator was assessed at South African sites by Clemence (1997), who showed the estimations to be satisfactory. The SWB model requires weather, soil, vegetation, irrigation water quality and management input data. The simulations was carried out for a different soil depth layers with volumetric soil water content at field capacity of $0.312(-33 \mathrm{~J}$ $\mathrm{kg}-1$ or $\mathrm{kPa})$ and a volumetric soil water content at permanent wilting point of $0.196(-1500 \mathrm{~J} \mathrm{~kg}-1 \mathrm{or} \mathrm{kPa})$.

The soil water balance model used during the investigation considers a number of inter-dependent soil parameters affecting saturated and unsaturated water flow during simulations and modelling. However, a simpler model should yield the same end result in the same order of magnitude. The model currently used was chosen due to its calibration and validation for South African conditions and capability to model anion and cation concentrations with fluctuating water content.

The results of the $2000 \mathrm{~mm}$ cover model are presented in Table 4 below. From the results we are satisfied that the cover thickness would be sufficient to sustain the crop through a relatively dry year.

Table 4 Annual average, standard deviation, maximum and minimum values and median of the soil water balance for sugar cane production with a rooting depth of $450 \mathrm{~mm}$ in a $2000 \mathrm{~mm}$ reconstituted soil, $699 \mathrm{~mm}$ rainfall per year

\begin{tabular}{|c|c|c|c|c|c|c|}
\hline Statistics & $\begin{array}{l}\text { Rainfall } \\
\left(\mathrm{mm} \mathrm{y}^{-1}\right)\end{array}$ & $\begin{array}{l}\text { Evaporation } \\
\left(\mathrm{mm} \mathrm{y}^{-1}\right)\end{array}$ & $\begin{array}{l}\text { Transpiration } \\
\quad\left(\mathrm{mm} \mathrm{y}^{-1}\right)\end{array}$ & $\begin{array}{c}\text { Drainage } \\
\left(\mathrm{mm} \mathrm{y}^{-1}\right)\end{array}$ & $\begin{array}{c}\text { Canopy } \\
\text { interception } \\
\left(\mathrm{mm} \mathrm{y}^{-1}\right)\end{array}$ & $\begin{array}{c}\text { Runoff } \\
\left(\mathrm{mm} \mathrm{y}^{-1}\right)\end{array}$ \\
\hline Average & 699 & 244 & 353 & 10 & 52 & 40 \\
\hline Stand. dev. & 142 & 36 & 92 & 24 & 7 & 28 \\
\hline Maximum & 1129 & 325 & 629 & 146 & 68 & 140 \\
\hline Minimum & 434 & 172 & 141 & 0 & 38 & 1 \\
\hline
\end{tabular}

\section{CONCLUSIONS}

In the absence of regulatory standards for closure, compounded by the evolving environmental legislation in South Africa, it is critically important to define and understand those aspects most likely to detract from the 
regulatory acceptance of rehabilitation efforts. We believe that a fundamental approach is required in order to demonstrate that rehabilitation is both sustainable and profitable. Our work has shown that soil water retention is the most critical aspect to soil restoration at Hillendale Mine. From the work completed to date, we know that we can use the footwall should there be no economically or technically viable deposition method to mix clay and sand to the required percentages. The minimum depth of the reconstituted soils should be $2000 \mathrm{~mm}$ in order to ensure crop production during anomalously dry years.

\section{ACKNOWLEDGEMENTS}

We would like to express our gratitude to Ticor South Africa and Kumba Resources for the permission to publish this work and to the dedicated mine personnel at Hillendale for whom rehabilitation has become a way of life.

\section{REFERENCES}

Allen, R.G., Pereira, L.S., Raes, D. and Smith, M. (1998) Crop evapotranspiration. Guidelines for computing crop water requirements, Irrigation and Drainage Paper No. 56, FAO, Rome, Italy 1998.

Birkland, P.W. (1984) Soils and Geomorphology, 372 p. Oxford University Press: New York.

Campbell, G.S. and Diaz, R. (1988) Simplified soil-water balance models to predict crop transpiration. In F.R. Bidinger and C. Johansen (eds), Drought Research Priorities for the Dryland Tropics, ICRISAT, India.

Chamley, H. (1989) Clay Sedimentology, 623 p., Springer-Verlag, Berlin.

Clemence, B.S.E. (1997) A brief assessment of a weather data generator (CLIMGEN) at South African sites. Water SA 23, pp. 271-274.

Fortmann, R.R. (1998) Report on the effects of future sugarcane production following mining operations at Hillendale farm. Unpublished Report, South African Sugar Association Experimental Station.

Gee, G.W. and Bauer, J.W. (1986) Particle Size Analyses: Laboratory Methods. Methods of Soil Analyses, Part 1. Physical and Mineralogical Methods. Agronomy Monograph no. 9: 2nd Edition, pp. 383-411. ASA-CSSASSSA, Madison, Wisconsin, United States of America.

Hillel, D. (1982) Introduction to Soil Physics. Academic Press Inc. Orlando, Florida, 32887.

Klute, A. (1986) Water Retention: Laboratory Methods. Methods of Soil Analyses, Part 1. Physical and Mineralogical Methods. Agronomy Monograph no. 9: 2nd Edition, pp. 635-662. ASA-CSSA-SSSA, Madison, Wisconsin, USA.

Monteith, J.L. (1977) Climate and efficiency of crop production in Britain. Philosophical Transactions of the Royal Society of London, Series B (281), pp. 277-294.

Nahon, D. (1986) Evolution of iron crusts in tropical landscapes. Rates of chemical weathering of rocks and minerals, S.M. Colman and D.P. Dether (eds), pp. 169-191, Academic Press, New York: London.

Richardson, C.W. and Wright, D.A. (1984) WGEN: A Model for Generating Daily Weather Variables. United States Department of Agriculture, Agricultural Research Services (1984).

Robbins, C.H. (1991) Solute transport and reactions in salt-affected soils. Agronomy Monograph no. 31: Modeling plant and soil systems, R.J. Hanks and J.T. Ritchie (eds), ASA-CSSA-SSSA, Madison, Wisconsin, USA.

Snyman, K. (2001) Inherent Natural Resources and Agricultural Potential of Hillendale Empangeni. Unpublished Report, LRI Associates.

Tanner, C.B. and Sinclair, T.R. (1983) Efficient water use in crop production: research or re-search? Limitations to Efficient Water Use in Crop Production, H.M. Taylor, W.R. Jordan and T.R. Sinclair (eds), ASA-CSSA-SSSA, 677 Madison, Wisconsin, United States of America, pp. 1-27.

Tinley, K.L. (1986) Coastal Dunes of South Africa. South African National Scientific Programmes Report, 109: 300 p.

Ware, C.I., Whitmore, G.P. and Uken, R. (2001) Evolution of the Northern KwaZulu-Natal Coastal Dune Cordon, South Africa, Evidence from Clays, International Heavy Minerals Conference, Fremantle, WA, 2001. 